\title{
Altruism and Exchange in Intergenerational Transfers: The Demand for Children Emergency Room
}

\author{
Ignacio Ortuño-Ortin ${ }^{1}$, Andrés Romeu ${ }^{2}$ \\ ${ }^{1}$ Department of Economics, University Carlos III, Madrid, Spain \\ ${ }^{2}$ Department of Economic Analysis, University of Murcia, Murcia, Spain \\ Email: aromeu@um.es
}

Received November 7, 2012; revised December 8, 2012; accepted January 9, 2013

\begin{abstract}
In this paper, we analyze the role of income as a determinant of parents' care for children. We show that the answer depends on whether Altruism or Exchange motives are the factors that explain intergenerational transfers. We then develop a test to discriminate between these alternatives. Unlike previous approaches, this test focuses on measures of parents' efforts on child care that are essentially non-monetary. Using data from the United States, we find a negative relationship between family income and the frequency of children's emergency room utilization which cannot be explained by several alternative controlling factors. In our framework, this is interpreted as evidence against the null of prominently altruistic behavior.
\end{abstract}

Keywords: Intergenerational Transfers; Altruism; Infant Health Demand

\section{Introduction}

Parents worldwide spend money, time and effort on the care and safety of their children. We investigate the nature of these transfers focusing on the two main competing paradigms prevailing in the literature. The altruistic behavior paradigm postulates that the welfare of children enters directly into the preferences of their parents. Altruism in this context was formalized early in the papers of $[1,2]$. From another perspective, parents may have an incentive to invest in their children if they expect some type of return in the future. This we will call the exchange hypothesis $[3,4]$.

Although it is immediate that both factors may lie behind the observed parental behavior, it is also known that they generate different predictions on several topics of household economics or economic policy, such as the design and implementation of public retirement systems. Therefore, it is important to quantify the relevance of each of these two paradigms in explaining the observable parental behavior. Some papers analyze monetary transfers such as bequests [5] or gifts [6], investment in education or many other monetary transfers. Their results are inconclusive, however, because it is hard to disentangle the part of these transfers that arises as a reaction to market imperfections from that which is purely altruistically motivated. The main reason is that there exists an income effect distorting the results when we consider monetary transfers such as education expenditures or bequests.
Thus, this paper focuses on a class of parental actions that are mostly non-monetary: the demand for child emergency room services (ER, henceforth). When a sudden fever or other signals are observed in a child, parents need to decide whether the symptoms require immediate medical attention or not. Beyond the monetary cost implied by their insurance, parents incur the opportunity cost of leaving their current tasks. We show that if such a cost was similar for rich and poor families, there is a relationship between the frequency of ER utilization and family income. Under altruism, the relationship should be positive and rich families would take their children to the ER more often than would poor ones. Under exchange, the sign of the relationship is ambiguous and could be even the opposite.

We test this point empirically using the frequency of child ER visits in the United States. The main data source is the 1999 and 2000 National Health Interview Surveys (NHIS, henceforth). In addition to health-related variables and medical service expenditure, the surveys include information on the socioeconomic conditions and health insurance status of the families helping us to control those factors that may affect the frequency of visits.

The parameters estimated in an ordered-choice model for ER frequency utilization show that poor parents use ER services more frequently, beyond what can be explained by differences in health conditions, education, and ease of access due to type of insurance. Thus, the negative sign on family income leads us to reject the 
altruistic hypothesis as a main factor driving the use of ER services. Furthermore, the data do not reject and are consistent with a theoretical prediction of the exchange model, namely, that the differences in the use of ER services between rich and poor should be smaller in economies with a low level of social mobility. The interpretation of these results deserves a word of caution: although both hypotheses may actually lay behind child upbringing in most other cases, our general conclusion is that the exchange hypothesis provides a better explanation of the observed parental behavior in the case of ER use.

\section{The Theoretical Model}

In this section, we propose a simple theoretical framework for the relationship between family income and ER visits. We abstract from fertility considerations and assume families consisting of one mother and a single child. Individuals in each generation live for two periods. In the first period, the child is a minor and the mother is the only one who works and consumes. The mother consumes her whole current income, $y_{p}$ in the first period so there are no savings or borrowings for the second period. During the first period the child might show symptoms potentially indicating a fatal illness that can have serious consequences but coursing with unspecific symptoms for instance, meningitis. Let us write $r=1$ if the child gets the disease and $r=0$ if she does not. The mother does not directly observe $r$ but an informative signal $s$. We denote the conditional probability that the child has the disease as $p(s) \equiv p(r=1 \mid s)$. We assume that $p(s)$ increases with the signal. Having observed the signal $s$, the mother must decide whether or not to take the child to the ER. Taking the child to the ER requires a non-monetary effort of magnitude $e$. Effort $e$ is assumed to be constant and independent of family income. It is reasonable to think that such an assumption is unrealistic, since rich and poor families might face a dissimilar value of $e$ in response to differences in ease of access to the health system or differences in the shadow price or opportunity cost of time. We will return to this discussion when presenting the empirical implications of the model.

The consequences of the child's health are revealed in the second period. If she had the disease during childhood but she was not treated, it is assumed that she becomes disabled in economic terms and her utility is zero. If the child was treated or did not have the disease, she becomes a healthy adult, able to work and consume. Children's income is random and takes the value $\varepsilon_{\mathrm{H}} y_{\mathrm{c}}$ with probability $1-\alpha$ and the value $\varepsilon_{L} y_{c}$ with probability $\alpha$, where $\varepsilon_{L}<1<\varepsilon_{H}$. The $y_{c}$ depends on the mother's first period income as $y_{c}=v\left(y_{p}\right)$ where the function $v(\cdot)$ is increasing and concave. Without loss of generality, we further assume that the mother's income in the second period is deterministic and again equal to first period's $y_{p}$ and that $\varepsilon_{L} \leq y_{p} / v\left(y_{p}\right) \leq \varepsilon_{H}$, i.e., a rich child is richer than her mother and a poor child is poorer than her mother.

\subsection{The Altruistic Hypothesis}

Back in the first period, the mother must decide whether to take her child to the ER when she observes s or not. An altruistic mother, as in [1] or [2], cares about the future welfare of her child by incorporating her child's utility in the second period. In other words, let $u_{p}(\cdot)$ be the utility function of the mother in the second period regarding their own consumption and $u_{c}(\cdot)$ the utility of her child. The mother's utility $U\left(c_{p}, c_{c}\right)$ is assumed to be quasi-linear in consumption, i.e.,

$$
U\left(c_{p}, c_{c}\right)=u_{p}\left(c_{p}\right)+\beta u_{c}\left(c_{c}\right) .
$$

During this second period, monetary transfers are allowed between the mother and the child. Let $b \geq 0$ be the transfer to the child in the second period. The budget constraint imposes the condition that $b \leq y_{p}$. To simplify the analysis, we will assume that the mother gives transfer $b>0$ to the child only when the child is poor and zero otherwise. If the degree of altruism towards the child is very high, parents may want to transfer even when the adult child is rich. However, the model is concerned with the decision of the parents regarding ER use in the first period. Decreasing marginal utility implies that the size of the bequest decreases with the child's income. Therefore, setting a bequest of zero for rich children does not alter the results on ER demand.

If the signal on child illness is very high, the mother will be impelled to take her child to the ER. If the illness does not reach a particular threshold, she will stay at home. Our primary interest is to characterize this threshold.

Proposition 1. Under altruism, there exists a decreasing threshold signal function $s_{U}\left(y_{p}\right)$ that makes mother indifferent between taking her child to the ER and not doing so.

Proof. If the mother decides to take her child to the ER she must solve the maximization problem:

$$
\begin{aligned}
& \max _{b}: \\
& \Pi^{E R} \equiv \alpha U\left(y_{p}-b, \varepsilon_{L} y_{c}+b\right)+(1-\alpha) U\left(y p, \varepsilon_{H} y_{c}\right)-\mathrm{e}
\end{aligned}
$$

with first-order conditions of $b^{*}$, interior solution of

$$
\beta=u_{p}^{\prime}\left(y_{p}-b^{*}\right) / u_{c}^{\prime}\left(\varepsilon_{L} y_{c}+b^{*}\right)
$$

The solution $b^{*}$ depends on $y_{p}$, the mother's income. If the mother decides not to take her child to the $E R$, she must solve 


$$
\begin{aligned}
\max _{b}: \Pi^{U} \equiv & (1-p(s))\left(\alpha U\left(y_{p}-b, \varepsilon_{L} y_{c}+b\right)+\cdots\right. \\
& \left.+(1-\alpha) U\left(y_{p}, \varepsilon_{H} y_{c}\right)\right)+p(s) u_{p}\left(y_{p}\right)
\end{aligned}
$$

with first-order conditions as above. Since $b^{*}$ is the same in both cases, the threshold $s$ that render the mother indifferent is given by the solution to $\Pi^{E R}=\Pi^{U}$. Differentiability and the implicit function theorem ensure the existence of a solution say $s\left(y_{p}\right)$. Now we want to show that $s\left(y_{p}\right)$ is decreasing in mother's income. Making $\Pi^{E R}=\Pi^{U}$ and simplifying terms we obtain:

$$
\begin{aligned}
& \alpha\left(u_{p}\left(y_{p}-b^{*}\right)+\beta u_{c}\left(\varepsilon_{L} y_{c}+b^{*}\right)\right)+(1-\alpha) \beta u_{c}\left(\varepsilon_{H} y_{c}\right) \\
= & \mathrm{e} / p(s)
\end{aligned}
$$

Since $p^{\prime}>0$ and $u_{c}\left(\varepsilon_{H} v\left(y_{p}\right)\right)$ is increasing in $y_{p}$, it is enough to show that

$$
u_{p}\left(y_{p}-b^{*}\right)+\beta u_{c}\left(\varepsilon_{L} v\left(y_{p}\right)+b^{*}\right)
$$

is increasing in $y_{p}$. Differentiating this expression, it suffices show that

$$
\begin{aligned}
& \beta u_{c}\left(\varepsilon_{L} y_{C}+b^{*}\right)\left(\varepsilon_{L} y_{C}+b^{*}\right) \geq \\
& u_{p}^{\prime}\left(y_{p}\right)-u_{p}^{\prime}\left(y_{p}-b^{*}\right)\left(1-b^{\prime *}\right)
\end{aligned}
$$

where $b^{\prime *}$ is the slope of $b^{*}$, solution to $\max _{b}: \Pi^{E R}$. Substituting the solution and simplifying, the condition now reads

$$
u_{p}^{\prime}\left(y_{p}-b^{*}\right)\left(1+\varepsilon_{L} v\left(y_{p}\right)\right) \geq u_{p}^{\prime}\left(y_{p}\right)
$$

Since $b^{*} \geq 0$ and $v^{\prime}(\cdot) \geq 0$, concavity of $u_{p}$ ensures that the above inequality holds.

Proposition 1 holds because the welfare of a child enters into the preferences of the mother as a normal good. A rich mother will value more the chance of giving bequests to her children so she will be more ready to pay cost e and the signal threshold that prompts her to act is lower.

Note that the cost $e$ has been assumed to be the same for rich and poor families, and the risk of illness $p(s)$ is also the same. Therefore rich mothers, facing a lower hurdle, will use the ER more often.

Claim 1. Ceteris paribus, if the altruistic hypothesis holds, rich families will make more intensive use of ER services.

The ceteris paribus clause above is intended to mean similar health conditions and similar cost of effort for the rich and the poor. Therefore, to obtain an empirical test that is valid, controls for family health, insurance, and other socioeconomic conditions are needed. This is explained in Section 3.

\subsection{The Exchange Hypohtesis}

Altruism may not be the only motivation behind mother's efforts. In many developing countries, the family is sometimes the only social institution for the care of the elderly. Although this is not the case in the developed world, there is some empirical evidence showing that children often make transfers to their parents when the latter are old $[7,8]$. Thus, if the mother expects some return from her child in the second period, she would have an incentive to raise a healthy child and to pay the cost e of taking her child to the ER after observing a signal. This we call the exchange hypothesis.

It is important to note that in this paper we do not model the decision of the child regarding transfers to the latter is old. There are three main approaches in the literature regarding this point: inverse altruism [9], social norms [10] and transfers in exchange for bequest [11], but the main results of our model are not affected by the specific channel and we just consider that the mother receives an amount $h>0$ from her child in the second period. For simplicity we will assume that the mother expect to receive $h$ only when her income is smaller than her child's and expects zero if the child is poor. ${ }^{1}$ We make the magnitude of $h$ depend on the mother's income, relative to her child's if the child is rich. Since $y_{c}$ depends on $y_{p}$, we will simply write $h\left(y_{p}\right)$.

The mother's payoff depends exclusively on her total consumption and the possible effort of taking her child to the ER:

$$
(1-\alpha) u_{p}\left(y_{p}+h\left(y_{p}\right)\right)+\alpha u_{p}\left(y_{p}\right)-\mathrm{e}
$$

If the child is not taken to the ER, then the expected utility is

$$
\begin{aligned}
& (1-p(s))\left[(1-\alpha) u_{p}\left(y_{p}+h\left(y_{p}\right)\right)+\alpha u_{p}\left(y_{p}\right)\right] \\
& +p(s) u_{p}\left(y_{p}\right)
\end{aligned}
$$

The signal threshold $s_{E}$ that makes (1) equal to (2) is characterized in the next proposition.

Proposition 2. Under the exchange hypothesis, there exists a threshold signal function $s_{E}\left(y_{p}\right)$ such that:

- If $h^{\prime}(\cdot) \leq 0$ then $s_{E}\left(y_{p}\right)$ is increasing.

- If $h^{\prime}(\cdot)>0$ then the sign of $s_{E}\left(y_{p}\right)$ is ambiguous.

Proof. Equating (1)-(2) and simplifying

$$
u_{p}\left(y_{p}+h\left(y_{p}\right)\right)-u_{p}\left(y_{p}\right)=\mathrm{e} /(1-\alpha) p(s)
$$

Let $s_{E}\left(y_{p}\right)$ be the solution. First, consider the case where $h$ is constant, i.e., $h^{\prime}=0$. In this case, by concavity of the utility function, the expression

$$
u_{p}\left(y_{p}+h\right)-u_{p}\left(y_{p}\right)
$$

is decreasing in the mother's income. As $p(\cdot)$ is in-

${ }^{1}$ In the United States the average wealth at age 50 is higher than the average wealth for people over 65 [12]. 
creasing, $s_{E}^{\prime}>0$. Following the same reasoning, the result also holds for $h^{\prime}<0$. In the case of $h^{\prime}>0$ though, we need a closed-form solution of $s_{E}\left(y_{p}\right)$ to determine the slope.

The first case is perhaps the most realistic: it may happen if a rich mother has a rich child and child-to-mother transfers are increasing in child's income. In that case $s_{E}\left(y_{p}\right)$ may be increasing under some particular conditions.

Proposition 3. Under the exchange hypothesis, if

$$
1+h^{\prime}\left(y_{p}\right)<u_{p}^{\prime}\left(y_{p}\right) / u_{p}^{\prime}\left(y_{p}+h\left(y_{p}\right)\right)
$$

holds and $h^{\prime}(\cdot)>0$ then $s_{E}^{\prime}(\cdot)>0$.

Proof. To obtain $s_{E}^{\prime}>0$, the term

$$
u_{p}\left(y_{p}+h\left(y_{p}\right)\right)-u_{p}\left(y_{p}\right)
$$

must be decreasing, i.e.,

$$
u_{p}^{\prime}\left(y_{p}+h\left(y_{p}\right)\right)\left(1+h^{\prime}\left(y_{p}\right)\right)-u_{p}\left(y_{p}\right)<0
$$

Rearranging, we obtain the desired condition.

The condition in proposition 3 holds depending on the size of $h^{\prime}\left(y_{p}\right)$. One case where it does is when children are altruistic towards parents and $h$ is assumed to be endogenously determined as the solution to the maximization problem of the child,

$$
\max _{h}: u_{c}\left(\varepsilon_{H} v\left(y_{p}\right)-h\right)+\mathrm{d} u_{p}\left(y_{p}+h\right)
$$

such that $h \geq 0$ where $\delta$ is the degree of altruism from the child to the parents.

Proposition 4. Consider the class of utility functions $u(x, t)=x^{1-} t /(1-t)$ and say $v\left(y_{p}\right)=k y_{p} \gamma$ concave function with $k>0$ and $0<\gamma<1$.

If

$$
(1+\delta-1 / t)\left(y_{p} /\left(\varepsilon_{H} k y_{p}^{\gamma}+y_{p}\right)\right)-k \gamma y_{p}^{\gamma-1} \geq 1
$$

then $s_{E}^{\prime}(\cdot)>0$.

Proof. The solution to the maximization problem of the child is given by

$$
h=\max \left[0, \varepsilon_{H} v\left(y_{p}\right) \delta^{1 / t} y_{p} /\left(1+\delta^{1 / t}\right)\right]
$$

For corner solutions with $h=0$ we would be in the case of the previous proposition. Otherwise, after substitution of $v\left(y_{p}\right)=k y_{p}^{\gamma}$ and $h$ interior solution in the condition

$$
u_{p}^{\prime}\left(y_{p}+h\left(y_{p}\right)\right)\left(1+h^{\prime}\left(y_{p}\right)\right)-u_{p}\left(y_{p}\right)<0
$$

the second part of the proposition follows.

There exist reasonable values of the parameters that meet condition (4). In Figure 1 we plot the shape of $s_{E}(\cdot)$ for different values of the parameters obtained from empirical sources. For instance, typical $[13,14]$ estimates of $\gamma$ range from 0.3 to 0.6 and we consider the cases of $\gamma=0.4,0.5$ and 0.6 cases. The remaining parameters are

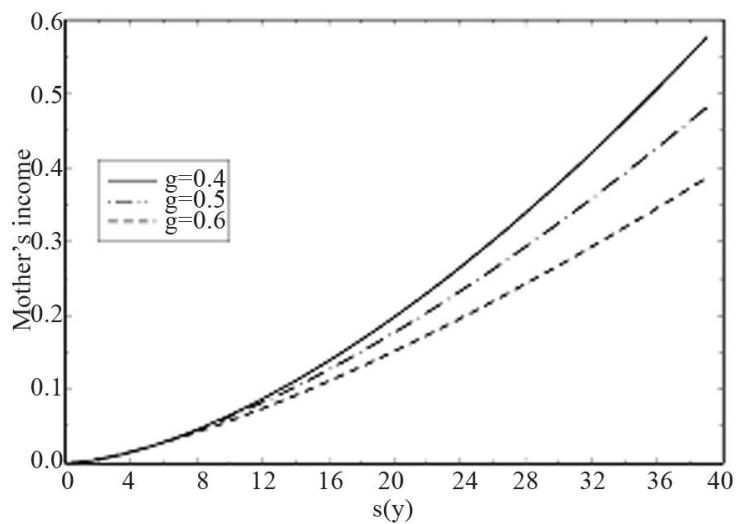

Figure 1. Signal threshold $s(\cdot)$ as a function of family income for different levels of the social mobility parameter $\gamma$.

taken as $\delta=0.45, \tau=2, k=20, \varepsilon_{H}=1.25$ and $\alpha=0.5$. The conditional probability of illness is simply taken as $p(s)=s$. The mother's income $y_{p}$ is in the range $(0-40)$. In all three cases function $s_{E}$ is increasing.

There is an interesting interpretation of the $\gamma$ parameter in the context of our model. This parameter controls the concavity of the $v$ function and is in fact an index of social mobility: a concave $v$ implies that, in expected terms, the child in a rich family will become relatively less rich than the parent. Thus, investing in the child yields a higher return in poor families than in rich families, the effect being stronger the lower $\gamma$ is. Moreover, in societies with a high level of social mobility (low values of $\gamma$ ) the gradient of the $s_{E}$ function will be smaller. In the empirical section of the paper we will show that the evidence does not seem to contradict this result.

\section{Data on the Demand for Child ER Services}

We collected data from the NHIS of the National Center for Health Statistics ${ }^{2}$ for the years 1999 and 2000. The basic purpose of the NHIS is to obtain information from US families on the amount and distribution of illness, the effects of the same in terms of disability and chronic impairments, and the kind of health services received in a sample of households across the 50 states. For each household with non-adult members a sample child is selected and the family respondent is prompted to answer questions regarding the child's health conditions. A total of 26,000 families with children were interviewed in 1999 and 2000. Our sample contains 3379 children of biparental families with at least one child between 0 and 5 years old, and covered by private insurance. We leave aside the uninsured or those covered by Medicaid since they have a reputation for abusing hospital emergency room services and not getting regular infant check-ups $[15,16]$.

${ }^{2}$ Data are publicly available at the Center for Disease Control website http://www.cdc.gov/nchs 
We use these data to build a test for the hypothesis that altruistic behavior is the main force driving ER demand. From the discussion in the previous section, this test should be based on the sign of the slope of the signal threshold function. Although the $s(\cdot)$ function is not observable, ER demand is. As explained in Claim 1, rich families should make more intensive use of child ER services, ceteris paribus.

Table 1 constitutes a first approach to this idea. We use the frequency of ER visits and family income to compute a cross-frequency table. Of the 5736 children who never went to the ER, 1702 live in families earning more than USD 75,000, 1134 in families earning between USD 55,000 and 75,000, 1334 in families earning between USD 35,000 and 55,000 and 1566 in the category of less than USD 35,000. Of the families in the top income category, $82.82 \%$ never visited the ER. This contrasts with the figure of $77.37 \%$ for the poorest. Moreover, if we consider those families that went at least once to the ER, the low-income families tend to show longer tails of frequency counts: for instance, of the 49 children who went four or five times to the ER, 18 lived in families earning less than USD 40,000 while only 11 fell in the category of more than USD 75,000.

The correlation in Table $\mathbf{1}$ constitutes a preliminary approach. Recall that Claim 1 is done under the assumption of a ceteris paribus, but there may exist several factors that can be correlated with family income and ER demand simultaneously that should be included in the specification.

First, health and income are related both in adults and in infants [17] even in developed countries such as the United States. Controls for health include child's age, which is a key factor to determine poor health risk in children, and dummy variables for having suffered allergic (asthma or digestive allergies) or infectious conditions (otitis, urine infections). Finally, the parents' assessment of a child's general health condition is also included in the specification.

Table 1. Cross-frequency table ${ }^{\mathrm{a}}$.

\begin{tabular}{|c|c|c|c|c|c|}
\hline \multirow[t]{2}{*}{ ER frequency of use } & \multicolumn{5}{|c|}{ Family Income $^{b}$} \\
\hline & $<35$ & $35-55$ & $55-75$ & $>75$ & Total \\
\hline 0 & 77.37 & 79.40 & 82.77 & 82.82 & 80.46 \\
\hline 1 & 13.83 & 13.99 & 12.41 & 12.94 & 13.34 \\
\hline $2-3$ & 7.31 & 5.71 & 3.94 & 3.70 & 5.25 \\
\hline $4-5$ & 0.89 & 0.60 & 0.73 & 0.54 & 0.69 \\
\hline $6-7$ & 0.25 & 0.06 & & & 0.08 \\
\hline $8-9$ & 0.25 & & 0.15 & & 0.10 \\
\hline $10-12$ & 0.05 & 0.18 & & & 0.06 \\
\hline $13-15$ & & 0.01 & & & 0.06 \\
\hline $16+$ & 0.05 & & & & 0.01 \\
\hline
\end{tabular}

${ }^{\mathrm{a}}$ Units are percentage points; ${ }^{\mathrm{b}}$ In thousands of USD.
Second, the education of parents is related to family income and is a key factor for properly identifying the nature of the signal. The link between education and income is well documented [18]; thus, richer parents may use ER services less simply because the conditional distribution of the signal differs between rich and poor. It can also be the case that richer more educated mothers have healthier babies at birth because they followed healthier habits during pregnancy [19]. The educational level of parents is included as a regressor in the specification.

Third, it has been shown that the proximity of health facilities could be correlated with family income [20] and for this reason we include dummy variables for the region of the household (North, West, Midwest and South) and its location in a metropolitan area.

Fourth, insurance companies have been progressively introducing health management organizations (HMO) that lie between the patient and the medical system and that control the access of families to hospital services. We include a dummy for the presence of a HMO in the family insurance.

Fifth, individuals make long-term decisions on the basis of permanent income, not current income. Measuring permanent income is problematic because it cannot be observed. The gap between permanent and current income is expected to shrink as the individual approaches retirement age; therefore, the estimated ER/income gradient may also be expected to differ for those individuals whose permanent income is not actually far from their current income. To capture this effect, we include the cross-product of income with a dummy that indicates whether the head of the family is older than 40 .

Sixth, the exchange model predicts that the slope becomes more negative the more concave $s(\cdot)$ is. To capture this effect, we include cross-products of income and the region of the United States.

The risk of accidents and the differences in the shadow price of time may also play a role. Regarding the first, the NHIS sample does not provide information on the accident history of the child. The literature ${ }^{3}$ is also inconclusive regarding how the risk of injury and income are related. Regarding the second, it is a factor of unobserved variability in our model, and its relationship to family income is in principle ambiguous. It is sensible to hypothesize that time is more expensive for the rich, and so the effort e should be more costly for rich families. However, rich families also have access to better technology and services regarding child care, such as more flexible

\footnotetext{
$\overline{{ }^{3} \text { Reference [21] found that Mexican American infants have smaller }}$ odds of homicide or unintentional injury than Whites, but Native Americans (and Blacks to a minor degree) have higher ones. Reference [22] use data from an interview and find no relevant correlation between income and risk of injury in Canadian adolescents.
} 
job schedules, own vehicle, baby-care or nursery services, etc., which could lower the cost of effort for the rich.

In addition to all the regressors above, dummies for sex, race, and Hispanic ethnicity of the children are also included.

The dependent variable is a categorical variable: ER demand expressed as intervals of the number of ER visits. For example, in the NHIS 2000, codes 1 to 7 are used for $0,1, \cdots, 6$ visits, code 8 for 13 to 15 visits, and code 9 for more than 16 visits $^{4}$. Standard linear least squares methods are inappropriate in this context as the dependent variable and the factors of interest are not linearly related. Thus, we propose a modified version of the standard ordered-choice models [23] where the latent variable is a count process. Put formally, let $\left\{y_{i}, \boldsymbol{x}_{i}\right\}$ for $i=1, \cdots, N$ be a random sample of ER demand ( $y$ with support $\{1, \cdots, J\})$ and $\boldsymbol{x}$ a vector of covariates. Variable $y$ is a transformation $y=T\left(y^{*}\right)$ from a latent count variable $y^{*}$ with probability function $g\left(\cdot \mid \boldsymbol{x}, \boldsymbol{\theta}_{0}\right)$ where $\boldsymbol{\theta}_{0}$ is a vector of unknown parameters. The conditional probability of observing $y_{i}$ is given by

$$
\operatorname{Prob}\left(y_{i} \mid \boldsymbol{x}_{i}, \boldsymbol{\theta}_{0}\right)=\sum_{j}\left[\mathrm{I}_{(y=j)} \sum_{i} g\left(y^{*} \mid \boldsymbol{x}_{i}, \boldsymbol{\theta}_{0}\right)\right]
$$

where $\mathrm{I}_{(\cdot)}$ is the indicator function. A maximum likelihood estimator (MLE) of $\boldsymbol{\theta}_{0}$ solves the problem of maximizing the sum of (7) for the whole sample.

\section{Main Results}

Table 2 reports the MLE estimates of the model for three different choices of $g(\cdot)$. A first step is to consider that the latent $y^{*}$ is a Poisson process with mean $\exp \left(\boldsymbol{x}^{\prime} \boldsymbol{\beta}_{0}\right)$. If the income is measured in logs, the corresponding $\boldsymbol{\beta}$ parameters can be interpreted as the income elasticity of expected ER demand. The first column of Table 2 reports this and the coefficients for some other variables of interest.

White children make less use of the ER than black or hispano and the frequency of use decreases with age, as expected. The regressors that control for poor health condition show a strong negative sign. Regarding family structure, the greater the number of siblings, having a step father and father education affects negatively the number of ER visits. The children of working mothers seem to use ER more frequently.

The income parameter is negative and significant at the $1 \%$ level. Roughly, each USD 10,000 increment in family income reduces the expected frequency of use of ER facilities by approximately $4 \%$, thus pointing in the direction of rejecting the null of altruistic behavior.

Still, we were concerned about the possibility that an

${ }^{4}$ In the NHIS 1999 data set there were only 6 categories corresponding to $0,1,2-3,4-9,10-12$ and more than 13 ER admissions.

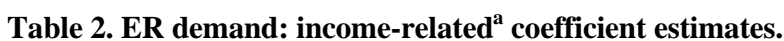

\begin{tabular}{|c|c|c|c|c|}
\hline \multirow[t]{3}{*}{ Parameters $^{\mathbf{b}}$} & \multicolumn{4}{|c|}{ Ordered count model } \\
\hline & \multirow[t]{2}{*}{ Poisson } & \multirow[t]{2}{*}{ NegBin } & \multicolumn{2}{|c|}{ Hurdle } \\
\hline & & & Probit & Count \\
\hline Constant & -0.500 & -0.426 & -1.061 & 0.778 \\
\hline Sex & 0.007 & 0.024 & 0.126 & -0.237 \\
\hline Age & -0.069 & -0.064 & -0.046 & -0.078 \\
\hline White & -0.287 & -0.290 & -0.164 & -0.390 \\
\hline Hispano & -0.067 & -0.072 & -0.205 & 0.320 \\
\hline Mother's education & 0.003 & -0.002 & -0.111 & 0.029 \\
\hline Father's education & -0.041 & -0.042 & -0.030 & -0.490 \\
\hline Step Mother & -0.403 & -0.297 & -0.488 & 0.071 \\
\hline Step Father & 0.812 & 0.714 & 0.703 & 0.532 \\
\hline Mother works FT & 0.104 & 0.096 & 0.060 & 0.137 \\
\hline No. sibling & -0.109 & -0.101 & -0.069 & -0.147 \\
\hline Infection & 0.421 & 0.398 & 0.383 & 0.181 \\
\hline Alergic & 0.408 & 0.425 & 0.331 & 0.282 \\
\hline Perceived Health & 0.196 & 0.183 & 0.134 & 0.216 \\
\hline Insurance HMO & -0.096 & -0.068 & -.0 .021 & -0.143 \\
\hline Urban & -0.332 & -0.341 & -0.303 & -0.201 \\
\hline Income & -0.041 & -0.039 & -0.008 & -0.115 \\
\hline Income \& Age $>40$ & -0.003 & -0.003 & -0.020 & 0.051 \\
\hline Midwest & 0.122 & 0.009 & -0.223 & 0.569 \\
\hline Northeast & 0.039 & -0.004 & 0.267 & -0.549 \\
\hline South & -0.123 & -0.163 & 0.113 & $-0.714^{*}$ \\
\hline Mid-W \& Income & -0.017 & -0.005 & 0.014 & -0.052 \\
\hline North-E \& Income & -0.036 & -0.032 & $-0.070^{*}$ & 0.069 \\
\hline South \& Income & 0.029 & 0.032 & -0.014 & $0.144^{*}$ \\
\hline \multicolumn{5}{|c|}{ Goodness of fit and specification tests } \\
\hline Average Loglik & -0.401 & 0.231 & 0.564 & \\
\hline Sample Size1 & 3379 & 3379 & 3379 & 724 \\
\hline LK ratio $p$-value & 0.000 & 0.0002 & 0.000 & \\
\hline Count & Actual $^{4}$ & & Fitted & \\
\hline 0 & 78.57 & 73.56 & 78.87 & 78.55 \\
\hline 1 & 15.12 & 21.68 & 14.15 & 14.08 \\
\hline 2.3 & 5.38 & 4.64 & 5.81 & 6.55 \\
\hline $4+$ & 0.91 & 0.10 & 1.16 & 0.80 \\
\hline Pearson's test & & 21.3 & 0.44 & 0.77 \\
\hline
\end{tabular}

${ }^{\mathrm{a}}$ The table shows a summary of the estimated coefficients for the incomerelated covariates. Estimates for the remaining socio-economic and health related variables are not shown and are available from the authors upon request; ${ }^{\mathrm{b}}$ Bold means significant at $5 \%$.

incorrect specification of the latent count process could bias the results. The bottom of Table 2 reports some measures of fit and specification tests. We computed the frequencies of the observed data and the predictions using the model estimates. The Poisson model fails to fit the frequencies of the observed counts, and a chi-squared Pearson test statistic rejects the null of a correct specification. 
The Poisson distribution is a one-parameter distribution with mean equal to variance: thus, it is not a good choice if the data show long tails and dispersion. In those cases, the negative binomial may help: if we denote as $\boldsymbol{\theta}_{0} \equiv\left(\boldsymbol{\beta}_{0}, \alpha_{0}\right)$ the parameter vector with $\alpha_{0}>1$ and $y^{*}$ is Negative Binomial with mean $\lambda_{0} \equiv \exp \left(\boldsymbol{x}^{\prime} \boldsymbol{\beta}_{0}\right)$, the variance of $y^{*}$ equals $\alpha_{0} \lambda_{0}$. Thus, the $\alpha_{0}$ parameter may account for the over-dispersion of the data.

The second column shows the results for a negative binomial specification. The negative binomial model improves the fit significantly and the Pearson test on the expected versus observed frequencies does not reject the null of a correct specification.

Our sample is also characterized by the presence of a huge number of zero visits: as reported in Table 1, zeros represent about $80 \%$ of the ER observations. One could think that all those zeros may contain a mixture of two different sub-samples of children: those who did not have any health problem or symptom during the year of the interview and those who did but whose parents did not go to the ER. This interpretation of the zero counts is appealing and introduces a higher degree of flexibility to the model. Thus, we specify a third model where the counts are the result of the mixture of two different processes: one driving the zero/non-zero outcomes and another accounting for the frequency counts conditional on a non-zero outcome observed. In such a "hurdle" model, we assume that $y_{1}^{*}, y_{2}^{*}$ are count latent variables for each process both negative binomial with probability functions $g_{1}\left(y_{1 i}^{*} \mid \boldsymbol{x}_{1 i}, \boldsymbol{\theta}_{0}^{1}\right)$ and $g_{2}\left(y_{2 i}^{*} \mid \boldsymbol{x}_{2 i}, \boldsymbol{\theta}_{0}^{2}\right)$. The conditioning variables in each of the processes may share some elements but all of them belong to the set of variables in $\boldsymbol{x}_{i}$. The data-generating process is defined as $y_{i}=0$ if $y_{i 1}^{*}=0$ and $y_{i}=y_{2 i}^{*}$ if $y_{i 1}^{*}>0$, and the probability function of the latent count process is given by the following expression:

$$
\begin{aligned}
g\left(y_{i} \mid \boldsymbol{x}_{i}, \boldsymbol{\theta}_{0}\right)= & I_{\left(y_{i}=0\right)} g_{1}\left(0 \mid \boldsymbol{x}_{1 i}, \boldsymbol{\theta}_{01}\right)+\cdots \\
& +I_{\left(y_{i}>0\right)} \frac{g_{2}\left(y_{i} \mid \boldsymbol{x}_{2 i}, \boldsymbol{\theta}_{02}\right)}{1 g_{2}\left(0 \mid \boldsymbol{x}_{2 i}, \boldsymbol{\theta}_{02}\right)}\left(1 g_{1}\left(0 \mid \boldsymbol{x}_{1 i}, \boldsymbol{\theta}_{01}\right)\right)
\end{aligned}
$$

Thus, under the hurdle model, the subpopulation of individuals who went at least once to the ER is allowed to differ in terms of its characteristics from the whole population [24]. Therefore, the income coefficient on the subpopulation of individuals who visited the ER at least once should include about only families who experienced at least one bad health episode and the income coefficient contains more information about the parents' decision which is what we are interested in. The last column of Table 2 shows the coefficients of this sub-sample. We still find a significantly negative elasticity between income and ER utilization. Moreover, this elasticity is significantly greater for people under 40, precisely where one would expect to find the greatest differences between current and permanent income. We also find that the elasticity differs significantly for different US regions and more specifically for the southern states.

Figure 2 plots the relationship between income and ER utilization in the four US regions. In the states of the South, where social mobility is lower [25], this relationship is much flatter. This result is in concordance with one the findings of the exchange model: a lower social mobility (greater $\gamma$ parameter) implies a flatter relationship between income and ER demand.

\section{Conclusions and Final Comments}

We propose a two-period theoretical model where parents have to decide whether to take their children to the emergency room or not. Their decision is analyzed under two competing frameworks: either parents are motivated by altruism or their decisions are based on contemplating children as an investment. Under generic altruism, rich parents should ceteris paribus take their children more often to the emergency room when faced with a given sign of illness. We find that this testable prediction is not verified in an ordered latent count model where the frequency of emergency room utilization is regressed on a set of covariates that include family income. We also find that explanations other than those predicted by an exchange model do not affect this main result. First, although rich families could have better access to preventive care and hence replace the need for emergency room utilization by more continued well-baby check-ups, this substitution effect is not enough to explain the magnitude of the gradient observed. Second, a similar result follows when we include controls for the differences between permanent and current income. And third, we find that the predictions of the exchange model in terms of the relation between income gradient and social mobility are not rejected by the evidence at hand.

The evidence presented here suggests that children

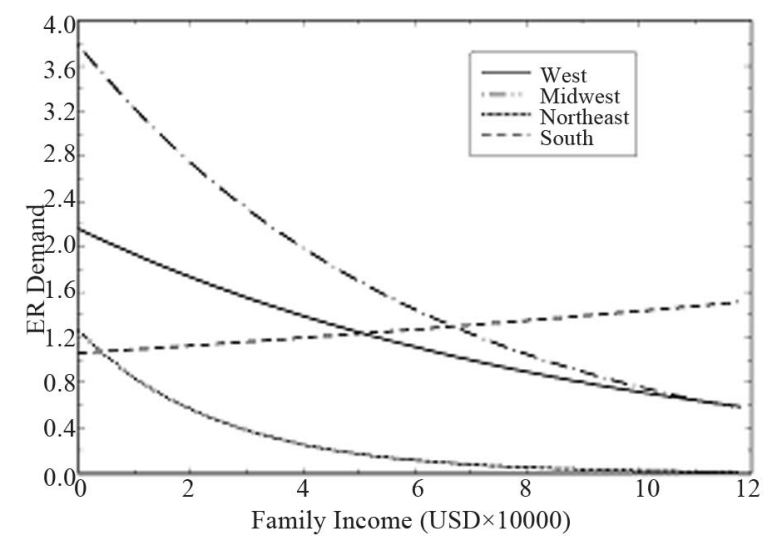

Figure 2. Child ER demand with respect to income in four US regions. 
might still play an important role as assets for parents' old age in developed economies. Integrating parents' health investment in children with fertility decisions will be part of further research on this issue. There are economic measures other than the health investment decision analyzed here and those already considered in the relevant literature that should also be studied. For instance, if our analysis is correct and children can be seen as an investment, parents might invest less in pension funds than would adults with no children. This and other similar empirical questions will also be analyzed in future work.

\section{Acknowledgements}

We thank Manuela Lopez-Azorín for her assistance in technical questions on child health, and Klaus Desmet for helpful discussion. We acknowledge the financial support received from the Ministerio de Educación, SEJ2007/67135ECON, ECO-2010-19830 and Fundación SENECA 11998-PHCS-09.

\section{REFERENCES}

[1] R. Barro, “Are Government Bonds Net Wealth?” Journal of Political Economy, Vol. 82, No. 6, 1974, pp. 10951117.

[2] G. Becker, "A Theory of Social Interactions." Journal of Political Economy, Vol. 82, No. 6, 1974, pp. 1063-1093. doi:10.1080/17405620903024263

[3] B. Bernheim, A. Shleifer and L. Summers, "The Strategic Bequest Motive," Journal of Political Economy, Vol. 93, No. 6, 1985, pp. 1045-1076. doi:10.1086/261351

[4] D. Cox, "Motives for Private Income Transfers," Journal of Political Economy, Vol. 95, No. 31, 1987, pp. 508-546. doi: $10.1086 / 261470$

[5] N. Tomes, "The Family, Inheritance, and the Intergenerational Transmission of Inequality," Journal of Political Economy, Vol. 89, No. 5, 1981, pp. 928-958. doi:10.1086/261014

[6] P. Menchik, "Primogeniture, Equal Sharing and the US Distribution of Wealth," Quarterly Journal of Economics, Vol. 94, No. 2, 1980, pp. 299-316. doi:10.2307/1884542

[7] K. McGarry and R. F. Schoeni, "Transfer Behavior in the Health and Retirement Study: Measurement and the Redistribution of Resources within the Family," The Journal of Human Resources, Vol. 30, 1995, pp. 184-226. doi:10.2307/146283

[8] K. A. Couch, M. C. Daly and D. A. Wolf, "Time? Money? Both? The Allocation of Resources to Older Parents," Demography, Vol. 36, No. 2, 1999, pp. 219-232. doi: $10.2307 / 2648110$

[9] M. Boldrin and L. E. Jones, "Mortality, Fertility and Saving Decisions in a Malthusian Economy," Review of Economic Dynamics, Vol. 5, No. 4, 2002, pp. 775-814. doi:10.1006/redy.2002.0186
[10] D. Cox and O. Stark, "Intergenerational Transfers and the Demonstration Effect," Boston College Working Papers in Economics No. 329, Boston College, Chestnut Hill, 1994. http://fmwww.bc.edu/EC-P/wp329.pdf

[11] L. Kotlikoff and A. Spivak, "The Family as Incomplete Annuities Market," Journal of Political Economy, Vol. 89, No. 2, 1981, pp. 372-391. doi:10.1086/260970

[12] S. Budriá-Rodríguez, J. Díaz-Gimenez and J. R. Rull, "Updated Facts on the US Distributions of Earnings, Income, and Wealth," Quarterly Review, Vol. 26, No. 3, 2002, pp. 1-35.

www.minneapolisfed.org/research/QR/QR2631.pdf

[13] G. Solon, "Cross-Country Differences in Inter-Generational Earnings Mobility," The Journal of Economic Perspectives, Vol. 16, No. 3, 2002, pp. 59-66. doi: $10.1257 / 089533002760278712$

[14] M. Corak, "Do Poor Children Become Poor Adults? Lessons from a Cross Country Comparison of Generational Earnings Mobility," IZA Discussion Paper No. 1993, 2006. http://ftp.iza.org/dp1993.pdf

[15] V. Sharma, S. Simon, J. Bakewell, E. Ellerbeck, M. Fox and D. Wallace, "Factors Influencing Infant Visits to Emergency Departments," Pedriatics, Vol. 106, No. 5, 2000 , pp. 1031-1039. doi:10.1542/peds.106.5.1031

[16] J. Billings and T. Mijanovich, "Emergency Room Use: The New York Story," In: Issue Brief, The Commonwealth Fund, New York, 2000.

[17] A. Case, D. Lubotsky and C. Paxson, "Economics Status and Health in Childhood: The Origins of the Gradient," American Economic Review, Vol. 92, No. 5, 2002. pp. 1308-1334. doi: $10.1257 / 000282802762024520$

[18] O. Ashenfelter and C. Rouse, "Schooling, Intelligence and Income in America," Princeton University Press, Princeton, 2000.

[19] J. Currie and E. Moretti, "Mother's Education and the Intergenerational Transmission of Human Capital: Evidence from College Openings," Quarterly Journal of Economics, Vol. 118, No. 4, 2003, pp. 1495-523. doi: $10.1162 / 003355303322552856$

[20] J. Currie and P. Reagan, "Distance to Hospitals and Children's Access to Care: Is Being Closer Better, and for Whom?" Economic Inquiry, Vol. 41, No. 3, 2003, pp. 378-391. doi:10.1093/ei/cbg015

[21] A. Jain, B. Khoshnood, K. Lee and J. Concato, "Injury Related Infant Death: The Impact of Race and Birth Weight," Injury Prevention, Vol. 7, No. 2, 2001, pp. 135-140. doi:10.1136/ip.7.2.135

[22] W. Pickett, M. Garner, W. Boyce and M. King, "Gradients in Risk for Youth Injury Associated with Multiple-Risk Behaviors: A Study of 11,239 Canadian Adolescents," Social Science and Medicine, Vol. 55, No. 6, 2002, pp. 1055-1068. doi:10.1016/S0277-9536(01)00224-6

[23] D. A. Greene and W. H. Hensher, "Modelling Ordered Choices: A Primer," Cambridge University Press, Cambridge, 2008.

[24] P. Deb and P. Trivedi, "Demand for Medical Care by the Elderly: A Finite Mixture Approach," Journal of Applied 
Econometrics, Vol. 12, No. 3, 1997, pp. 313-336. doi:10.1002/(SICI)1099-1255(199705)12:3<313::AID-JA E440>3.0.CO;2-G

[25] D. I. Levine and B. Mazumder, "Choosing the Right Parents: Changes in the Intergenerational Transmission of
Inequality between the 1970s and the Early 1990s," Working Papers 2002-08, Federal Reserve Bank of Chicago, Chicago, 2002.

http://www.escholarship.org/uc/item/9r45b10r.pdf;origin $=$ repeccitec 